\title{
Research on the Green Marketing Strategy of Enterprises in the Context of Circular Economy
}

\author{
Peng Ji \\ Zhejiang Post and Telecommunication College; Shaoxing Zhejiang 312016 China
}

Keywords: circular economy; enterprises; green marketing; problems; strategies.

\begin{abstract}
Circular economy is a new development model combining economic development with resource utilization and environmental protection. With the continuous expansion of circular economy market in China, many enterprises have begun to develop the circular economy and achieved a win-win situation in terms of environmental and economic benefits. Under the circular economy model, green marketing has become a new marketing concept and marketing method as well as a marketing strategy for Chinese enterprises. China should attach importance to the concept of green marketing and continuously implement marketing strategies. In order to jointly achieve the goal of sustainable development in China, the concept of green marketing is an inevitable choice for the development of enterprises. They can formulate long-term green marketing strategies and plans according to the green marketing concept, so as to create green brands and implement green services. Relevant strategies were proposed in this paper for enterprises to implement green marketing, which will help to improve their overall competitiveness.
\end{abstract}

\section{Introduction}

Circular economy is to implement economic operation based on the economic environment and the material cycle. It integrates resources, "green" production and sustainable consumption to realize a cyclical model, emphasizing the harmony between the economy and the natural ecological environment. Enterprises can meet the market's demand for green products by satisfying the standards of recycling, reuse and reduction. Nowadays, with the emphasis on sustainable development and circular economy in China, green marketing has become a new marketing strategy in the production and operation process of enterprises.

\section{Establishing Green Marketing Concept}

\subsection{Concept of Green Marketing -- Inevitable Choice for Enterprises}

In order to achieve the goal of sustainable development in our country, modern enterprises should take the protection of the environment and green culture as their important business ideas. It is feasible for them to start from consumers' green consumption, take reducing the damage to the ecological environment as the center and protecting the ecological environment as their purpose, and constantly stick to the sustainable development as the marketing mode. The green marketing mode is to select and formulate a scientific and rational marketing strategy mainly based on the circular economy mode. Its purpose is to make full use of green marketing activities in the enterprise's production and operation and to combine their own interests with the interests of consumers and the ecological environment. On this basis, enterprises can constantly explore and discover market opportunities, design products and services and complete sales, which can not only satisfy the needs of consumers, but also achieve a long-term strategy for sustainable economic development. The concept of green marketing adapts to the living environment and economic development today and is also the development direction of our country, so it is an inevitable choice for enterprises.

\subsection{Enhancing Green Corporate Culture}

At present, the implementation of green marketing is a strategic decision of enterprises, and therefore changing the values is their top priority. Under the circular economy development mode, enterprises need to convert existing production and management concepts and establish the concept of green marketing. It is also necessary to enhance the green culture of enterprises and form a certain 
green cultural atmosphere, that is, a green corporate culture enables enterprises, consumers and the ecological environment to co-exist. Enterprises need to effectively instill green awareness in all aspects of corporate culture, conduct green education for employees and implement green management. Green logos to the enterprise products can encourage enterprises to change and improve green marketing activities, thus effectively promoting them to enter in to the green market.

\subsection{Resource Values -- the Main Content of Establishing Green Marketing}

Under the green marketing concept, enterprises must understand and consider the value of resources correctly. The value of resources not only refers to the resources themselves, but also includes the environmental costs incurred during the use of resources. Therefore, enterprises must have resource values in their green development.

\subsection{Improving the Employee Quality and Establishing Learning-Style Enterprises}

The most critical aspect of the enterprise's application of green marketing concept is to improve the quality of employees. The effective approach is to establish the learning-style enterprise to allow employees to advocate knowledge and love learning. It is helpful to cultivate all-round and comprehensive quality of employees, thereby improving the quality of enterprise personnel, which will play a certain role in enhancing the company's green concept.

\section{Developing Measures for Green Marketing}

\subsection{Establishing a Survey System for Green Information}

Enterprises need to establish a green system for information research and conduct in-depth market research. They can explore and analyze the potential demand for green consumption by collecting information about consumption, green technology and green resources, and then use market research data as the basis for developing green marketing.

\subsection{Developing a Sound Plan for Green Marketing}

The development of a reasonable plan for green marketing has a fundamental role in the implementation of enterprises' production and green marketing. When developing green marketing plans, they need to define marketing tasks and make reasonable plans based on marketing goals and directions. The green plan formulated by an enterprise must be consistent with its long-term development strategy, so as to ensure that resources are fully utilized.

\subsection{Carrying out Green Management and Implementing Green Competition}

China's enterprises have adopted effective means to promote green operation and management by developing long-term green development strategies. Scientific and rational market positioning of an enterprise's products and brands can effectively integrate its green marketing resources and formulate specific measures. This can promote its green production and technological innovation to meet the green needs of consumers, thus forming a certain advantage in the market. The success of an enterprise in market competition lies in its marketing measures to protect the environment. This is a necessary condition for the long-term development of the enterprise and it is also the focus of its green marketing strategy, which plays a decisive role in market competition.

\subsection{Constantly Building Green Brand and Implementing Green Certification Project}

Enterprises must create green products in accordance with relevant regulations and standards as well as the standards of product quality. It is feasible to apply for certification according to the industry's characteristics, the size of the enterprise, the degree of internationalization and other aspects of the actual situation, or strive to create conditions conducive to the application for certification. In addition to giving green connotations to its brands in the implementation process of brand strategy, the enterprise must reflect products' cultural background, show the green concept, enrich the carrying capacity of the brand and constantly expand the brand depth, so as to reflect the brand value.

\section{Implementing the Green Product Marketing Strategy}

\subsection{Highlighting the Development of Green Products}

In the development of green products, the enterprise needs to look for relevant information and then makes an evaluation after comprehensive analysis. First of all, it is essential to look for and 
gather the demand information related to green products, and the product demanded in the market may be found after a round of market analysis. Afterwards, the enterprise can find and select market opportunities conducive to its development by evaluating the market. At the same time, it should also develop green products suitable for modern society in a timely manner based on the needs of the current market.

The product development must be implemented accompanied by strict green quality management. Green products begin with seeking creativity. First of all, it is needed to identify whether the creativity meets the green needs and whether it will harm the natural environment, and then form a concept based on the product. A series of links including the formulation of relevant marketing strategies and market trials require to be effectively managed. At the same time, the harm to the ecological environment during the production and consumption process should be taken into account.

During the production, enterprises are supposed to adopt non-polluting production technologies and equipment, which will help to reduce the damage to the ecological environment and product contamination. They must not only pay attention to the purchase of materials and product structure, but also needs to strictly control all related aspects such as the nature, functions, design and manufacturing of the products, in order to use resources effectively and enhance awareness of environmental protection and energy conservation. Renewable energy which is easily decomposable should be used in production. Green products are responsible for people's health and safety as well as environmental protection.

In the packaging of products, it is necessary to use non-toxic and decomposable materials for packaging, so as to achieve the recycling of resources. However, enterprises must consider the safety of products while improving the repeated utilization of resources. In addition, the impact on the product must be considered in all aspects of product transportation and storage. Research and development of new green packaging materials is also a way to achieve green products, which is conducive to ensuring the supply of green products and effectively achieving the basic purpose of green consumption.

\subsection{Formulating Green Product Prices Reasonably}

At present, the continuous development of science and technology and environmental protection measures are constantly improving at the same time, which promotes the cost decline of manufacturing green products. When formulating the price for a green product, enterprises should notice that consumers' acceptance of commodity prices is in line with their consumption concept. While formulating price standards for green products, various factors should be comprehensively considered, such as production cost, production capacity, market demand and market potential. Enterprises should collect and analyze market information in a timely manner and combine consumer psychology with the actual situation, so as to formulate a reasonable green product price plan. Nowadays, people's economic income keeps increasing and their environmental awareness has also improved. Therefore, green products can not only bring good benefits to enterprises, but also help them gain certain advantages under current market competition.

\subsection{Developing Green Product Marketing Strategy}

In the implementation of green product marketing, the following points should be noted. The first is to choose good channel providers, because they are the bridge between production and consumption and play a role in the distribution of products. Enterprises should choose channel providers with good reputation to facilitate the maintenance of the product's green image. In order to promote marketing of green products, it is needed to establish stable green marketing channels and relationship with good marketing partners. Secondly, attention should be given to related work in the marketing process, such as tasks in all aspects of transportation, storage and handling. Fundamental work of such kind must be completed very well. The last one is to create dedicated channels for green marketing. In the initial stage, franchise stores for green products can be established first to ensure that all goods in the franchise store are pure green products, which is beneficial to consumers' understanding of green products. 


\subsection{Completing Related Green Marketing Activities}

The specific activities of green marketing are to continuously guide consumers to deliver green information and finally promote purchase behavior under the needs of consumers. Its main purpose is to establish a green image of the enterprise and expand its reputation through such activities and to enrich the meaning of green marketing, so as to effectively promote the consumption and promotion of green products. These green marketing activities must not only consolidate the position of green products in the market, but also integrate the enterprise's interests and goals. The most important thing in green marketing is the power of brand marketing. Consumers often select products relying on brands due to the limitations of awareness, and thereby building their awareness of and trust in brands of the enterprise is the top priority. To create a green brand image, the enterprise must take feasible measures in various aspects, such as brand design, advertising and sales services.

First of all, the green positioning of products should be achieved through advertisements, so that consumers can understand and accept the true meaning of advertising. A large number of green advertisements can be put into the market to create a green atmosphere, which is conducive to inspiring consumers' desire to purchase. Then, the marketing staff can explain and demonstrate the function of green products to consumers through marketing and promotion at the sales site, aiming at publicizing green product information. Respondence to actual questions of consumers can deepen their understanding of products, thereby promoting their purchases. It is also feasible to attract more consumers' interest through some trial activities, special promotions, etc. Green PR also plays a role in green marketing activities. An enterprise can create a certain social foundation for its green marketing by establishing contact with the mass through some special activities like playing related materials and participating in public welfare activities of environmental protection, helping them understand the business in the supply, production and sales links. This kind of green propaganda is indispensable in the green product marketing activities because it can deliver the enterprise's information and viewpoints to consumers in a timely manner through media. Enterprises can take the current green marketing needs in the market as a starting point and plan meaningful mass activities that are socially beneficial on the premise of complying with the law. The dissemination and propaganda through the media can not only achieve the purpose of expanding the popularity of the enterprise, but also enhance its green image so that the green products can be better sold.

\subsection{Developing and Innovating Green Services}

In the process of green marketing, enterprises need to continuously innovate and develop green services, reintegrate green service processes and conduct green services effectively in a timely manner to achieve customer satisfaction and enhance customers' desire for consumption as well as confidence in the products, which is conducive to establish a friendly and long-term relationship with them.

It is possible to innovate and develop green services through green service channels. This can not only facilitate the communication and exchanges between consumers and suppliers to solve the aftersales problems in a timely manner, but also provide a bridge for the enterprise to collect customer information. Special attention should be given to some aspects in the process of opening green service channels. The first is to prevent consumers from misunderstanding of green consumption. The second is to correctly guide consumers to consciously consume and solve the problems that they have in the consumption effectively from a professional perspective. The third is to realize the value of green products in service and allow consumers to enjoy the greatest satisfaction through thoughtful and detailed humanized green services.

\section{Conclusion}

Implementing the green marketing strategy is an inevitable choice in the context of the circular economy. Enterprises should take effective measures to comprehensively promote the marketing of green products so as to promote the development of circular economy in China. 


\section{References}

[1]. Jia Ning. Analysis of the Path Selection of Green Marketing for Anhui SMEs from the Perspective of Circular Economy [J].Economic \& Trade Update,2017(06):41-43.

[2]. Wu Feimei, Chen Chun. Research on Green Marketing Strategy of Enterprises Based on Circular Economy Market__ A Case Study of INCOM Resources Recovery Resourcing Co., Ltd. [J]. Journal of Heihe University,2016,7(04):34-36.

[3]. Zhang Huiqi, Xu Dongnan. Study on the Problems and Countermeasures in the Process of Enterprise Green Marketing [J]. Heilongjiang Science, 2016, 7(16): 144-145.

[4]. Zou Jilong. Discussion on the Problems and Countermeasures of Green Marketing of China's SMEs [J]. Market Modernization, 2016(14): 62-63.

[5]. Wang Sujuan, Chen Na. Research on the Green Marketing Strategy of Coal Enterprises under the Background of Circular Economy [J]. Coal Technology, 2013, 32(08): 14-15. 